\title{
Correlations between some Parameters of Raw and Stored Semen in Boar
}

\author{
Iulian IBĂNESCU ${ }^{1,2^{*}}$, Petru ROȘCA ${ }^{1}$, Ioana CRIVEI ${ }^{1}$, Ioana SFARTZ ${ }^{1}$, Dan DRUGOCIU ${ }^{1}$ \\ ${ }^{1}$ University of Agricultural Sciences and Veterinary Medicine of Iasi, Faculty of Veterinary Medicine, Aleea \\ M. Sadoveanu no. 3, 700490, Iasi, Romania \\ ${ }^{2}$ Besamungsverein Neustadt a. d. Aisch e.V., Karl-Eibl-Straße 23, 91413, Neustadt an der Aisch Germany \\ *Corresponding author: iulian.ibanescu@yahoo.com
}

Bulletin UASVM Veterinary Medicine 72(2) / 2015,

Print ISSN 1843-5270; Electronic ISSN 1843-5378

DOI:10.15835/buasvmcn-vm: 11453

\begin{abstract}
The preservation in liquid form, at $17^{\circ} \mathrm{C}$ for several days is still the most used method of semen preservation in boar. In these conditions, it would be of great value to know the factors that can predict the capacity of an ejaculate to maintain its biological value over preservation period. This study aimed to identify the correlations between some parameters of raw semen, and those of extended semen, stored in liquid form, for three days at $17^{\circ} \mathrm{C}$. Over 1000 ejaculates were collected by means of manual method and artificial vagina over a period of two years from 400 mature boars housed in a specialized unit in Germany. The semen was examined immediately after collection (before dilution) as well as after three days of preservation. All the parameters (except the volume) were determined by means of computerized instruments. The examination of raw semen was performed using SQA-Vp, while the stored semen was analyzed using Spermvision version 3.7. All data were processed with IBM SPSS Statistics version 21. The Pearson correlation revealed no strong correlation between any of the raw semen parameters when analysed together with stored semen parameters. However, some moderate or weak correlations were found, for example a positive correlation between motility of raw semen and motility of stored semen $(\mathrm{p}<0.01)$, a positive correlation between percentage of morphological normal sperm in raw semen and the motility of stored semen ( $\mathrm{p}<0.01$ ), a negative correlation between the concentration of raw semen and the linearity and wobble coefficient in stored semen $(\mathrm{p}<0.01)$ as well as a couple other weak correlations. We conclude that, despite the fact that some correlations were revealed, unfortunately the analyzed parameters of raw semen have low predictive value on the parameters of extended semen after preservation $a 7^{\circ} \mathrm{C}$, and that the parameters of semen will behave differently from one ejaculate to another.
\end{abstract}

Keywords: boar, correlation, extended, raw, semen

\section{INTRODUCTION}

Optimization of animal breeding, including pigs, implies a detailed knowledge of the events that take place during reproduction. Since the implementation of artificial insemination in pigs, there was a continuous interest related to variations of seminal parameters, especially in what concerns the boars of high genetic value (Tardif et al., 1999).

Although the main seminal indicators determined within the general examination of raw boar semen (volume, concentration, motility, total number of spermatozoa/ejaculate) seem to have low predictive value on the litter size or pregnancy rate (Schulze et al., 2013), they might correlate with the parameters on preserved semen. Thus, a better knowledge of these correlations would be of a great help for the semen production centers, giving them the possibility to select only the ejaculates with good preservability.

The preservation in liquid form, at $17^{\circ} \mathrm{C}$ for several days is still the most used method of semen 
preservation in boar, maintaining higher sperm fertility compared with freezing method ( $\mathrm{Hu}$ et al., 2015).

Although sperm freezing represents a more desirable method, offering many advantages in example the facilitation of the distribution of agriculturally desirable genes, the help in controlling the transmission of certain pathogens, thereby protecting the health status of the herd, the minimization of the effects of a sudden outbreak of a contagious illness or a natural disaster (Bailey et al., 2008), unfortunately boar sperm are more sensitive to hypothermic shock, suffering more pronounced biochemical and functional disorders compared to other species, which leads to reduced motility, viability and transport in female genital tract, thus affecting the fertilizing potential (Silva et al., 2015). Therefore, compared with fresh semen, the use of post-thawed boar spermatozoa results in about $10-25 \%$ reduced conception or farrowing rates and 2-3 decreased total litter size (Zeng et al., 2014). This constrains the frozenthawed semen to be used usually only in case of transferring valuable genetic material between swine breeding centers (Roca et al., 2011) and maintains the preservation in liquid state, at room temperature $\left(15-20^{\circ} \mathrm{C}\right)$ as the standard method in case of boar semen.

Over the time, several authors tried to find correlations between the parameters of raw or extended semen and the ability to fertilize the oocytes (Flowers, 1997; Hirai et al., 2001; Sutkeviciene et al., 2005; McPherson et al., 2014). However, we couldn't find much data regarding the correlations between the parameters of raw semen and those of preserved semen, although we consider this to be of great value for semen productions centers. Usually, within semen processing, the ejaculates showing less than 60$70 \%$ total motility are discarded before dilution, the threshold value being different according to the management of the production center. Still, of the selected ejaculates, some will have low quality after preservation, which will make them improper to be used for insemination. In these conditions, it would be of great value to know the factors that can predict the capacity of an ejaculate to maintain its biological value over preservation period, because the best results in swine reproduction can be obtained only using semen of a high quality for artificial insemination.
This study aimed to identify the correlations between some parameters of raw semen, and those of extended semen, stored in liquid form, for three days at $17^{\circ} \mathrm{C}$.

\section{MATERIALS AND METHODS}

Over 1000 ejaculates collected over a period of two years from 400 mature boars housed in a commercial unit in Germany specialized in the production of doses for artificial insemination of sows were analyzed. The collection was performed by means of manual method, with double glove (Bogdan, 1999) and by means of artificial vagina using a procedure similar to that described by Barrabes Aneas et al., (2008) with an interval of about 7 days between two successive collections from the same boar. Only the ejaculates showing at least $65 \%$ total motility were processed, all the rest were discarded.

The dilution was carried out with the diluent BTS $®$ (Minitube, Tiefenbach, Germany) and the evaluation was performed in two steps. The first step was executed on raw semen, within 10 minutes after ejaculation, using (except for volume) the SQA-Vp device (A-Tech, Medical Electronic Systems Ltd, Los Angeles, CA, USA), and the following parameters were determined: volume, concentration, total motility, total number of motile sperm $/ \mathrm{ml}$ (TMS/ml), percentage of morphologically normal sperm (\%Morph), total number of sperm/ejaculate (TS/Ej), total number of motile sperm/ejaculate (TMS/Ej), total number of morphologically normal spermatozoa/ ejaculate (TMorphNS/Ej) and total number of motile and morphologically normal spermatozoa/ ejaculate(TMMorphNS/Ej). The second step was executed after dilution and three days of preservation in liquid state, at $17^{\circ} \mathrm{C}$ in tubes of 100 $\mathrm{ml}$ (90 $\mathrm{ml}$ semen $+10 \mathrm{ml}$ air). For this assessment we used SpermVision software version 3.7 (Minitube of America - MOFA®, Verona, WI, USA) connected to a Zeiss Axio Scope.A1 (Carl Zeiss MicroImaging GmbH, Göttingen, Germany) optical microscope equipped with a plate warmed at $38^{\circ} \mathrm{C}$ and the following parameters were determined: total motility (TMot), progressive motility (PMot), average path velocity (VAP), curvilinear velocity (VCL), straight line velocity (VSL), straightness (STR), linearity (LIN), wobble (WOB), amplitude of lateral head displacement (ALH), beat cross frequency (BCF). Settings were adjusted as 
follows: for total mobility parameter it were taken into account sperm showing any movement, but for progressive mobility parameter have been considered only moving sperm presenting an average speed (VAP) of minimum $25 \mu \mathrm{m} / \mathrm{s}$ and a coefficient of straightness (STR) of at least 0.3.

The data stored in the computer were processed using the software IBM SPSS ${ }^{\circledR}$ Statistics version 21 (IBM $^{\circledR}$ Corporation, Chicago, IL, USA). Results are presented as mean values and standard deviation (SD). In order to signal the presence of possible correlations between parameters of raw semen and those of preserved semen, the Pearson correlation (2-tailed) has been used.

\section{RESULTS AND DISCUSSION}

In the nextpages are presented the correlations between each of the raw semen parameters and the parameters of extended semen.

\section{Volume}

Pearson correlation analysis showed three significant correlations. A negative correlation with progressive motility and beat cross frequency and a positive one with amplitude of lateral head displacement (Tab. 1).

A higher volume of the ejaculate indicates a higherquantity ofseminal plasma, as approximately $93 \%$ of semen volume in boar is represented by seminal plasma (Ciornei, 2012). This seems to have a negative impact on the motility and beat cross frequency after preservation but at a small scale, given the low value of correlation $(r=-0.81$ and -0.135 respectively). The positive correlation with amplitude of lateral head displacement is also negligible.

\section{Concentration}

Four significant correlations, albeit weak, were detected between concentration and the parameters after preservation (Tab. 2).

Sperm concentration is an indirect indicator of spermatogenesis and should always be evaluated in association with semen volume within a quantitative examination of an ejaculate. Besides its role in modulating the number of insemination doses, this parameter seems to correlate sometimes with the conception rate (Haugan et al., 2007). A higher values for concentration indicates a smaller quantity of seminal plasma (and thus a higher quantity of extender) per spermatozoon.

As the concentration correlated in our study positively with curvilinear velocity but negatively with straightness, linearity and wobble coefficient, it can be stated that, although at a low level (given the small values of correlation), a higher number of sperm per volume unit in the ejaculate will lead to an enhancement of their speed after preservation, but with a less steady path. A less regular movement of sperm in case of higher density would be something to expect, given the smaller spaces between the cells and thus an inevitable higher number of collisions. However, the semen dilution regulates the number of sperm/ $\mathrm{ml}$, aiming to obtain a standard concentration for each insemination dose. In these conditions, it was surprising to observe that a higher sperm concentration in raw semen seems to affect the regularity of sperm path even after dilution and storage.

\section{Total motility}

As expected, a positive correlation was found between total motility in raw semen and both total

Tab. 1. Correlations between volume of ejaculate and seminal parameters after preservation

\begin{tabular}{lcccccccccc}
\hline & TMot & PMot & VAP & VCL & VSL & STR & LIN & WOB & ALH & BCF \\
\hline Volume & -0.060 & $-0.081^{* *}$ & 0.011 & -0.006 & 0.031 & 0.031 & 0.029 & 0.027 & $0.065^{*}$ & $-0.135^{* *}$ \\
\hline *. Correlation is significant at the 0.05 level(2-tailed) \\
**. Correlation is significant at the 0.01 level (2-tailed)
\end{tabular}

Tab. 2. Correlations between concentration of raw semen and seminal parameters after preservation

\begin{tabular}{|c|c|c|c|c|c|c|c|c|c|c|}
\hline & TMot & PMot & VAP & VCL & VSL & STR & LIN & WOB & $\mathrm{ALH}$ & $\mathrm{BCF}$ \\
\hline Conc. & -0.036 & -0.014 & 0.011 & $0.078^{*}$ & -0.036 & $-0.074^{*}$ & $-0.116^{* *}$ & $-0.144^{* *}$ & 0.043 & 0.058 \\
\hline
\end{tabular}


and progressive motility in preserved semen (Tab. 3).

It is well known that a high value of sperm motility is essential for the fertilization process (Runceanu et al., 2007). The fact that the total motility in raw semen correlates with total and progressive motility in preserved semen might be the reason why most of semen production centers eliminate before dilution the ejaculates showing less than $60-70 \%$ total motility, the threshold value being different according to the management of the center.

However, the correlations found in our study are only moderate ( $r=0.242$ and 0.238 ), which indicates that an ejaculate with high motility could often result in insemination doses with moderate or low motility and vice versa. The severe drop that appears in some cases for motility values after storage might be due some morphological issues of sperm, chemical deficiencies of seminal plasma or microbiological burden of semen, which cannot be evaluated through the general examination of fresh semen.

No other significant correlation was identified between motility of raw semen and the indicators of preserved semen in boar, showing that a higher percent of motile sperm in raw semen will not affect their velocity after storage nor the regularity of their movement.

\section{Total number of motile sperm/ml}

This parameter is a combination between the total motility and the concentration. Its correlations with the parameters of preserved semen are quite similar with those of concentration, namely weak negative relation with straightness, linearity and wobble coefficient and weak positive relation with curvilinear velocity (Tab. 4). On the other hand, there is no correlation with total or progressive motility in extended semen, as showed by raw semen motility. This could suggest that the total number of motile sperm $/ \mathrm{ml}$ is modulated rather by the semen concentration than by total motility.

In addition, there is a positive correlation (albeit weak) with beat cross frequency. All these together suggest that a higher number of motile spermatozoa/ml in raw semen will tend to influence the spermatozoa to move faster but less linear after preservation.

\section{Percentage of morphologically normal spermatozoa}

The percentage of morphologically normal spermatozoa within an ejaculate is one of the most important parameters in terms of semen quality. A small amount (between 5 and 10\%) of abnormal spermatozoa is normal within a boar ejaculate (Drugociu, 2009), but if this proportion exceeds $25 \%$ then the whole ejaculate should be discarded (Gadea, 2002). The reason for this is that only morphologically normal spermatozoa are capable to survive after preservation and to fertilize the oocyte (Runceanu et al., 2007). Thus, a high amount of abnormal sperm would impair the fertilization process.

In our study, moderate positive correlations were found between this parameter and both total and progressive motility after preservation (Table $5)$.

Tab. 3. Correlations between total motility in raw semen and seminal parameters after preservation

\begin{tabular}{lcccccccccc}
\hline & TMot & PMot & VAP & VCL & VSL & STR & LIN & WOB & ALH & BCF \\
\hline $\begin{array}{c}\text { Total } \\
\text { motility }\end{array}$ & $0.242^{* *}$ & $0.238^{* *}$ & 0.058 & 0.026 & 0.052 & 0.013 & 0.035 & 0.051 & 0.015 & 0.013 \\
\hline $\begin{array}{l}* \text { * Correlation is significant at the 0.05 level(2-tailed) } \\
\text { *. Correlation is significant at the 0.01 level (2-tailed) }\end{array}$
\end{tabular}

Tab. 4. Correlations between total number of motile sperm $/ \mathrm{ml}$ in raw semen and seminal parameters after preservation

\begin{tabular}{lcccccccccc}
\hline TMot & PMot & VAP & VCL & VSL & STR & LIN & WOB & ALH & BCF \\
\hline TMS $/ \mathrm{ml}$ & 0.022 & 0.042 & 0.027 & $0.083^{* *}$ & -0.019 & $-0.068^{*}$ & $-0.103^{* *}$ & $-0.126^{* *}$ & 0.045 & $0.068^{*}$ \\
\hline *. Correlation is significant at the 0.05 level (2-tailed) \\
**. Correlation is significant at the 0.01 level (2-tailed)
\end{tabular}


Also, weak positive correlations were signaled with average path velocity and straight line velocity. Thus, it seems that a higher percentage of normal sperm in the ejaculate will provide more motile and faster spermatozoa after preservation.

The significance of VAP is still controversial. While some authors (Holt et al., 1997; Park, 2013) report a negative correlation between VAP and parturition rate, others (Didion, 2008) state that a positive, but weak correlation exists between these coefficients. Although a higher speed would help the spermatozoa to reach the fertilization site in a shorter time, this also implies a more intense metabolism of the sperm cells thus a faster consumption of energy resources.

Contrary to our results, other authors (Nöthling et al., 1997) found no correlations between the percentage of spermatozoa with normal morphology in fresh semen and the motility post-preservation, after they performed a study on dog semen and used freezing as the method of preservation. This suggests that not only the sperm species but also the preservation method can influence the correlation between the parameters of fresh and stored semen.

\section{Total number of spermatozoa within the entire ejaculate}

This parameter is probably the most important in terms of semen quantity, modulating the number of insemination doses produced and offering important information regarding the spermatogenesis rate. It seems to be even more important than semen concentration, which is not is not a direct measure of testicular function as final semen volume includes secretions from the seminal vesicles and prostate. Additionally, it was shown to be related to various fertility endpoints in humans (Dearing, 2014).

Although a more intense spermatogenesis, with the production of a higher number of spermatozoa within a time interval is one of the desiderata of the semen production centers, this could also mean a less effective sperm formation process, with a higher number of low quality sperm through the accelerated activity. However, in order to draw a certain conclusion regarding the spermatogenesis rate, the testicular volume should be taken into account.

In our study, only weak correlations were signaled between the total number of spermatozoa and the parameters after preservation (Tab. 6), namely positive correlations with curvilinear velocity and amplitude of lateral head displacement and negative correlations with total motility, progressive motility, linearity and wobble coefficient.

The wobble coefficient is defined by the ratio between the average path velocity and curvilinear velocity, indicating that, the higher its value is, the more efficient is the path of spermatozoa. As the total number of spermatozoa is negatively correlated with this coefficient, but also with linearity and motility, we may think that, at a higher rate of spermatogenesis, the quality of spermatozoa could be affected, showing lower preservability.

Total number of motile spermatozoa within the ejaculate

Showing the ability of the testicles to provide a higher or a lower number of sperm capable

Tab. 5. Correlations between the percentage of morphologically normal spermatozoa in raw semen and seminal parameters after preservation

\begin{tabular}{lcccccccccc}
\hline & TMot & PMot & VAP & VCL & VSL & STR & LIN & WOB & ALH & BCF \\
\hline \%Morph & $0.268^{* *}$ & $0.268^{* *}$ & $0.070^{*}$ & 0.024 & $0.071^{*}$ & 0.023 & 0.055 & $0.077^{*}$ & 0.001 & 0.042 \\
\hline *. Correlation is significant at the 0.05 level(2-tailed) \\
*. Correlation is significant at the 0.01 level (2-tailed)
\end{tabular}

Tab. 6. Correlations between the total number of spermatozoa within the entire ejaculate and seminal parameters after preservation

\begin{tabular}{|c|c|c|c|c|c|c|c|c|c|c|}
\hline & TMot & PMot & VAP & VCL & VSL & STR & LIN & WOB & ALH & $\mathrm{BCF}$ \\
\hline $\mathrm{TS} / \mathrm{Ej}$ & $-0.077^{*}$ & $-0.071^{*}$ & 0.017 & $0.063^{*}$ & 0.000 & -0.030 & $-0.076^{*}$ & $-0.110^{* *}$ & $0.081^{* *}$ & -0.042 \\
\hline
\end{tabular}


to move towards the fertilization site, this parameter represents a combination between the percentage of total motility and the total number of spermatozoa within the ejaculate. Similar to $\mathrm{TS} / \mathrm{Ej}$, it showed weak, positive correlations with curvilinear velocity and amplitude of lateral head displacement as well as weak, negative correlations with linearity and wobble (Tab. 7). However, no correlations were found with total and progressive motility.

Again, we may think that, a higher value of this parameter will tend to determine the spermatozoa in preserved semen to move faster but less linear.

Total number of morphologically normal spermatozoa within the ejaculate

As this parameter is directly modulated by the total number of sperm within the ejaculate it showed also only weak correlations, namely a positive correlation with curvilinear velocity and a negative correlation with wobble and amplitude of lateral head displacement (Tab. 8).

These results may lead to same conclusions as in case of total number of sperm and total number of motile sperm within the ejaculate.

Total number of motile and morphologically normal spermatozoa within the entire ejaculate
This parameter refers to probably the most important spermatozoa within an ejaculate, namely those that have the ability to move towards the fertilization site, but possess also an unimpaired membrane, considering that the morphologic integrity of the sperm is an essential condition for their involvement in the fertilization process (Runceanu et al., 2007). An ejaculate showing a higher value for this parameter would assure the production of a higher number of insemination doses, with better quality. However, only weak correlations were found between this parameter and the kinetic parameters of preserved semen (Tab. 9).

The correlations are almost identically with those showed by TMorphN/Ej: weak, positive relations with VCL and ALH and a weak, negative relation with WOB.

\section{CONCLUSIONS}

We conclude that, despite the fact that some correlations were revealed, unfortunately the parameters of raw semen have low predictive value on the parameters of extended semen after preservation at $17^{\circ} \mathrm{C}$. Only weak or moderate correlations were revealed, which have too little

Tab. 7. Correlations between the total number of motile spermatozoa within the entire ejaculate and seminal parameters after preservation

\begin{tabular}{lcccccccccc}
\hline TMot & PMot & VAP & VCL & VSL & STR & LIN & WOB & ALH & BCF \\
\hline TMS/Ej & -0.019 & -0.014 & 0.031 & $0.068^{*}$ & 0.014 & -0.026 & $-0.066^{*}$ & $-0.096^{* *}$ & $0.084^{* *}$ & -0.036 \\
\hline *. Correlation is significant at the 0.05 level(2-tailed) \\
*. Correlation is significant at the 0.01 level (2-tailed)
\end{tabular}

Tab. 8. Correlations between the total number of morphologically normal spermatozoa within the entire ejaculate and seminal parameters after preservation

\begin{tabular}{|c|c|c|c|c|c|c|c|c|c|c|}
\hline & TMot & PMot & VAP & VCL & VSL & STR & LIN & WOB & ALH & $\mathrm{BCF}$ \\
\hline TMorphN/Ej & 0.005 & 0.010 & 0.039 & $0.070^{*}$ & 0.023 & -0.022 & -0.059 & $-0.086^{* *}$ & $0.082^{* *}$ & -0.027 \\
\hline
\end{tabular}

Tab. 9. Correlations between the total number of motile and morphologically normal spermatozoa within the entire ejaculate and seminal parameters after preservation

\begin{tabular}{|c|c|c|c|c|c|c|c|c|c|c|}
\hline & TMot & PMot & VAP & VCL & VSL & STR & LIN & WOB & ALH & $\mathrm{BCF}$ \\
\hline TMMorphN/Ej & 0.056 & 0.059 & 0.047 & $0.069^{*}$ & 0.033 & -0.017 & -0.047 & $-0.069^{*}$ & $0.080^{* *}$ & -0.022 \\
\hline
\end{tabular}


value in order to draw a certain conclusion. Most of these correlations may suggest that a higher density of raw semen and a higher production of spermatozoa will determine the sperm cells to move faster but more erratic after preservation. However, as the values of correlations were low, it seems that the parameters of semen will tend to behave differently from one ejaculate to another.

Acknowledgements. This study was conducted under the frame of European Social Fund, Human Resources Development Operational Programme 2007-2013, project no. POSDRU/159/ $1.5 / \mathrm{S} / 132765$.

The authors want to thank Besamungsverein Neustadt an der Aisch, Germany, for their support during the study.

\section{REFERENCES}

1. Bailey JL, Lessard C, Jacques J, Brèque C, Dobrinski I, Zeng W, Galantino-Homer HL (2008). Cryopreservation of boar semen and its future importance to the industry. Theriogenology 70:1251-1259.

2. Barrabes Aneas S, Gary BG, Bouvier BP (2008). Collectis $®$ automated boar collection technology. Theriogenology 70:1368-1373.

3. Bogdan AT (1999). Tratat de reproducţie şi însămânţări artificiale la suine. Ed Tehnică Agricolă, București, 118120.

4. Ciornei ŞG (2012). Materialul seminal de vier şi biotehnologii de reproducţie la suine. Editura "Ion Ionescu de la Brad", Iaşi, 44-48.

5. Dearing Chey Gordon (2014). Sources of Uncertainty Impacting Upon Sperm Cryopreservation for Cancer Patients. Doctoral Thesis, Imperial College Healthcare NHS Trust, London, 45.

6. Didion BA (2008). Computer-assisted semen analysis and its utility for profiling boar semen samples Theriogenology 70 (8):1374-1376.

7. Drugociu D (2009). Bolile obstetrical-ginecologice la animale, Ediţia a II-a. Editura „Ion Ionescu de la Brad”, Iaşi, 140-141.

8. Flowers WL (1997). Management of boars for efficient semen production. J Reprod Fertil 52:67-78.

9. Gadea J (2002). Sperm under the microscope. Pig Int 32:24-27.

10. Haugan T, Gröhn YT, Kommisrud E, Ropstad E, Reksen 0 (2007). Effects of sperm concentration at semen collection and storage period of frozen semen on dairy cow conception. Animal Reproduction Science 97(1-2):1-11.

11. Hirai M, Boersma A, Hoeflich A, Wolf E, Foll J, Aumuller TR (2001). Objectively measured sperm motility and sperm head morphometry in boars (Sus scrofa): relation to fertility and seminal plasma growth factors. J Androl 22:104-110.

12. Holt C, Holt WV, Moore H.DM, Reed HCB, Curnoc RM (1997). Objectively measured boar sperm motility parameters correlate with the outcomes of on-farm inseminations: results of two fertility trials. J Androl 18:312-323

13. Hu S, Zhang X, Han C, Wei S, Xie D, Du R, Hu J (2015). Effects of Three Different Diluents on Quality of Boar Semen Stored at $17^{\circ} \mathrm{C}$. Journal of Northeast Agricultural University 22(2):36-46.

14. McPherson FJ, Nielsen SG, Chenoweth PJ (2014). Semen effects on insemination outcomes in sows. Animal Reproduction Science 151:28-33.

15. Nöthling JO, Gerstenberg C, Volkmann DH (1997). Semen quality after thawing: correlation with fertility and fresh semen quality in dogs. J Reprod Fertil Suppl 51:109-16.

16. Park S (2013). Effects of sow, boar, and semen traits on sow reproduction. Thesis for the Degree of Master of Science, University of Nebraska-Lincoln.

17. Roca J, Parrilla I, Rodriguez-Martinez H, Gil MA, Cuello C, Vazquez JM, Martinez EA, (2011). Approaches towards efficient use of boar semen in the pig industry. Reprod Domest Anim 46(2):79-83.

18. Runceanu L, Cotea C, Drugociu D, Roşca P (2007). Reproducție, obstetrică şi ginecologie veterinară. Ed. "Ion Ionescu de la Brad", Iași, 164-171.

19. Schulze M, Ruediger K, Mueller K, Jung M, Well C, Reissmann M (2013). Development of an in vitro index to characterize fertilizing capacity of boar ejaculates. Anim Reprod Sci 140(1-2):70-76.

20. Silva CG, Cunha ER, Blume GR, Malaquias JV, Báo SN, Martins CF (2015). Cryopreservation of boar sperm comparing different cryoprotectants associated in media based on powdered coconut water, lactose and trehalose. Cryobiology 70:90-94.

21. Sutkeviciene N, Andersson MA, Zilinskas H, Anderson $M$ (2005). Assessment of boar semen quality in relation to fertility with special reference to methanol stress. Theriogenology 63:739-47.

22. Tardif S, Laforest JP, Cormier N, Bailey JL (1999). The importance of porcine sperm parameters on fertility in vivo. Theriogenology 52(3):447-59.

23. Zeng C, Peng W, Ding L, H Lian, Zhang Y, Fang D, Tang $\mathrm{K}$ (2014). A preliminary study on epigenetic changes during boar spermatozoa cryopreservation. Cryobiology 69:119-127. 